students of domestic animals (33 and 4 more under the heading of animal husbandry); conservationists (2); zoology teachers (37). Others, presumably 'pure', branches of zoology, are represented by these figures: morphology (75); physiology (55); embryology (78); zoogeography (9); general ecology (3); ecology of vertebrates (301); (no heading for ecology of invertebrates); invertebrate zoology (39); vertebrate zoology (68); ornithology (140); teriology (108); herpetology (24); ichthyology (342); malacology (12); protistology (19); human anatomy (4); soil zoology (10); history of zoology (11); histology (48). A very low number of geneticists (8) is, perhaps, less surprising to see than only five "Darwinists", and there are no more than two biophysicists and two biometricians; there are, apparently, no biochemists (unless they are listed as physiologists) and only one experimental zoologist. When all groups are added to- gether, the total number is 3,250 , that is, about 500 more than in the alphabetical list; this is because many persons indicated more than one speciality.

The system of classification is such that it is almost impossible to see what proportion of zoologists is carrying out basic research and what is engaged in practical applications. A glance through the list of entomologists and the institutions where they work suggests that, probably, more than half of them are engaged in pest control. If the same applies to zoologists and ecologists working, for example, on rodents and other economic animals, it appears that the great majority of Soviet zoologists is engaged in applied work.

Although admittedly incomplete and somewhat out of date, the list will be useful to zoologists in other countries who may wish to exchange publications with their Soviet colleagues.

\title{
COMMONWEALTH SCHOLARSHIP COMMISSION
}

T HE second annual report* of the Commonwealth Scholarship Commission shows that there were 168 Commonwealth scholars studying at United Kingdom universities and colleges during 1960-61. In the I961 compotition, 232 candidates have accepted the offer of scholarships, 40 of them coming from India, 28 from Canada and 22 from both Australia and Pakistan.

One feature of the report will lead to some disquiet. The Commission made a preliminary examination of the problem which it is likely to face in considering applications for extension of tenure in and after the third year of the Commonwealth Scholarship and Fellowship Plan. A number of scholars have accepted two-year awards and has been admitted to courses of research for which three years of study are needed if the holder is to obtain the doctorate at which he aims. For such scholars to return to their country with their research half-completed, and without a qualification, will engender frustration and militate against the realization of the aims for which the Commonwealth Scholarship and Fellowship Plan was instituted. At the Commonwealth Education

* Commonwealth Relations Office: Colonial Office. Second Annua Report of the Commonwealth Scholarship Commission in the United Kingdom for the year ending 30th September 1961. Pp. 36. (London: H.M.S.O., 1962.) 2s. $3 d$. net.
Conference in 1959 it was anticipated that most candidates would, on taking up awards, have already had some postgraduate experience which would enable them to obtain a higher degree in the United Kingdom with two years further work. It is found, however, after two years experience of selection of candidates for United Kingdom awards, that a majority of them enter the competition in the final year of their course for a first degree or its equivalent and are judged to need at least three years further work if they are to proceed to a Ph.D. on their scholarship. It is therefore expected that a substantial number of the 1960 scholars will have good grounds for asking for an extension of tenure for a third year. The Commonwealth Scholarships Act, 1959, prescribes that not more than 500 awards may be held at any one time. If the statutory limit remains unaltered, and during 1961-62 the Commission wishes to extend the tenure of a substantial number of the 1960 awards for a third year (that is, tenure during 1962-63), it will have to choose between granting such third-year extensions and making, in the 1962 competition, the total of 250 fresh awards which it would normally seek to make. There would thus be a clash between the claims of existing scholars and the expectations of the several countries making now nominations.

\section{FORESTRY RESEARCH IN BRITAIN}

T H.E report* on forest research for the year ended March 1960, issued by the Forestry Commission, contains accounts of the research work carried out by the Forestry Commission research staff and by workers attached to universities and other institutions, most of whom are aided by grants from the Forestry Commission. In it there are a number of good photographs, but some of these would have been improved by the inclusion of an object to provide a comparison of size. The general trend of the research work is in keeping with the developmental stage the Forestry Commission has reached, and it is also indicative, in some measure, of what is likely to become normal practice in the fairly near future.

- Forestry Commission. Report on Forest Research for the year ended March 1960. Pp. viii $+203+16$ plates. (London: H.M.S.O. 1961.) 12s. net.
Afforestation is still a dominant work in which the Forestry Commission is engaged, and must hope to be engaged for some time to come. Afforestation problems are being investigated on difficult sites, including disused sand and gravel workings, on areas overlying impermeable clay and on exposed and elevated sites. But more and more attention is now being directed to the problems of existing forests such as their improvement, stand structure and regeneration. Large areas of forest have been established on peat, and this medium contains particular difficulties which are not easy to overcome. It requires draining; few tree species can be grown on it; the stability of the trees is often precarious; and there is now evidence, after some years, of a deficiency of potash and other elements in pine stands established successfully by deep draining and cultivation of the peat and aided 
by phosphatic fertilizers applied at the time of plant. ing. It is also realized that somo pure stands may be improvod by transforming them into mixtures, and so long-term experiments have been established for this general purpose which also include a comparison of the effect of pure and mixed stands on soil conditions.

Considerable attention to the soil is being given by way of fortilizer trials on sand dunes and on deep peat, by soil analyses and studies of the breakdown of litter by the soil microfauna. The effect of wind on Britain's forosts is a major consideration and so studies continue to be mado on windblows, tho stability of trees and stands and the recording of airflow in relation to shelterbelts.

Nylon netting, as a cheaply orected alternative to conventional netting, and wire-strand foncing for exclusion of deer from regeneration areas are showing encouraging results. Another line of research in forest protection is the use of herbicides to maintain efficient, non-inflammable firebroaks. Although successful results have been obtained, a limiting factor to their use is the exponse, and thus it seems unlikely that they will be used except for particular cases where the high cost can be justified.

After eleven years of experience of pruning conifers by disbudding, the conclusions roached are that it has been a failure with some species and not sufficiently successful with the others to warrant it being applied on a forest scale. So Britain's now forests are no longer in danger of having grotesque tufted poles scattered through them.

Those responsible for directing and implementing the research work of the Forestry Commission are to be congratulated on the good results that have been obtained and on publishing them in such an attractive manner.

C. J. TAylor

\title{
INTERSTELLAR COMMUNICATION AND HUMAN EVOLUTION
}

\author{
BY PROF. ROBERT ASCHER \\ Department of Sociology and Anthropology, Cornell University \\ AND \\ PROF. MARCIA ASCHER \\ Department of Mathematics and Physics, Ithaca College, New York
}

G. COCCONI and P. Morrison have recently - entertained the possibility of interstellar communication 1 .

More recently a seareh for signals from other civilizations was considered by von Hoerner2. In the later article it is pointed out that the potential of a scarch is largely depondent on the adequacy of guesses about the probability of the existence of extraterrestial technical civilizations, the probable stage of development of a civilization which wo might contact, the longevity of attempts at contact following success or failuro, and the result of possible contact and exchange. Attention is given to the determination of these and othor factors and some numorical estimates are suggested. Presumably this and similar investigations will form the basis for the design of listening and sending apparatus. This ambitious and expensive endeavour may benefit by using models founded on human evolution as well as extraterrestial data, and constructed with tho end of increasing the reasonableness of the guesses. This article indicates initial steps in this direction.

The use of a model or series of models which involve human evolution is necessarily based on two assumptions. We assume that throughout hominid history, since the origin of hominids and culture, there has existed sufficient curiosity to motivate attempts to contact sclf-conscious life-forms and some means of doing so. Secondly, wo assume that the cffectiveness of the barriers which separated different populations during prehistoric times was equivalent to the offectiveness of the barrier which now separatcs Farth civilization from possible extraterrostrial civilizations. The first assumption is supported in interprotations of the archxological and fossil hominid records and in behavioural studies of tho higher primates and othor advanced mammalian forms, 'Tho second nssumption is tenablo because for most of prehistory the only moans of communication was bipedal locomotion. Fxtensive bodies of water, in particular, were restrictive to contact between small terrestrial populations. Both assumptions are related by opposition; curiosity encouraged contact and effective barriers inhibited it.

In order to construct the proposed models some definitions used in the recont article in Science are re-cast. There, a technical civilization is defined by the "presence of highly advanced radio techniques"; here, a technical civilization is defined by the pressence of barrier-surmounting techniques, irrespective of the barrier or the techniques. This reformulation is not only necossary for the inclusion of relevant informa. tion but is also necessary for the entire endeavour. It would be shortsighted and inhibiting to future ideas on communication to view possible extra terrestrial civilizations enthnocentrically, or rather. electrocentrically, by supposing that the highest form of communication now reached on Earth is the highest form that will be reached hore or can be: roachod elsewhere. Along with this, we substitute contact activities for contact signals. Even if withinvision deviees, such as large fires, were used as contact signals in prehistoric times, they would be difficult for the prehistorian to locate, impossible to interpret with confidence, and are not directly relevant to the barrier-surmounting problems with which we are concerned. On the other hand, ovidence of contact activities such as intrusive tools are the data with which the student of human evolution is familiar.

Within the context of the prosent problem, wo tentatively divide prehistory into two technical orders and call tho first carly prehistory and the second, lator prchistory. The principal critorion for this division is the barrier-surmounting technique or techniques which existed during each ordor. The analogy betweon prehistoric contact and oxchange, and hypothesized extraterrestrial contact and exchange, is suggested in tho following description.

Early prehistory bogins with the origin of hominids and technology more than $1,000,000$ years ago and 